\title{
Academic Success in College: Socioeconomic Status and Parental Influence as Predictors of Outcome
}

\author{
Devin L. Merritt, Walter Buboltz* \\ Department of Psychology, Louisiana Tech University, Ruston, USA \\ Email: dlm056@latech.edu, Buboltz@latech.edu
}

Received 11 February 2015; accepted 25 May 2015; published 28 May 2015

Copyright (C) 2015 by authors and Scientific Research Publishing Inc.

This work is licensed under the Creative Commons Attribution International License (CC BY).

http://creativecommons.org/licenses/by/4.0/

(c) (i) Open Access

\begin{abstract}
Bandura (1986) postulated that beliefs about one's ability (self-efficacy) were better predictors of achievement than ability itself [1]. Therefore, in academics, the higher the beliefs that a student develops regarding his or her ability to succeed in school, the greater the likelihood that he or she will attain academic success. Although academic goals vary among students, academic self-efficacy appears to be essential in order for academic aspirations to be achieved. Multiple factors, including socioeconomic status (SES) are related to academic self-efficacy. Past research has noted that SES influences academic attainment [2] [3]. Familial backgrounds, such as SES [4] and parental influence [5], have been found to impact academic achievement. This study examined the relationship between socioeconomic status, academic self-efficacy, and perceived success in college. A total of 298 undergraduate students from a southern university completed self-report measures that consisted of sociodemographic questions, the Multidimensional Scales of Perceived Self-Efficacy (MSPSE), and the Perceptions of Parental and Teacher Academic Involvement. Results indicated that SES was significantly related to self-efficacy, and parental influence was a significant predictor of academic self-efficacy. Results also showed that parental involvement mediated the relationship between familial SES and self-efficacy.
\end{abstract}

\section{Keywords}

Self-Efficacy, Socioeconomic Status, Parental Involvement, Academic Performance

\section{Introduction}

The ancient Greek philosopher Herclitus made the immortal statement, “Change is the only constant” (trans.

${ }^{*}$ Corresponding author.

How to cite this paper: Merritt, D.L. and Buboltz, W. (2015) Academic Success in College: Socioeconomic Status and Parental Influence as Predictors of Outcome. Open Journal of Social Sciences, 3, 127-135.

http://dx.doi.org/10.4236/jss.2015.35018 
1968). With the onset of a global society, and a global market, major changes are being brought about in regard to employment and careers. Ever more pressing is the need for higher education and training to succeed and advance in today's global economy. With employers looking for more educated personnel to hire, necessary preparation and determination to enroll in and graduate from college are a major change facing modern families.

Research has been devoted to examining the differences between various groups and specific attributes that may lead to success or attrition in college [6] [7]. Results from these studies suggest that socioeconomic status (SES) is likely to play a role in the academic progression and success of students [8]. Socioeconomic status (SES) represents the availability of important social, educational, and economic resources that a family has [9]. Tucker-Drob and Harden (2012) proposed that SES was also a demographic factor that had a profound effect on cognitive abilities. Genetic influences have been found to account for roughly $50 \%$ of academic performance, whereas the other $50 \%$ is related to environmental influences [4]. Environmental influences are manifested through a number of indirect modalities that are related to familial SES [10]. Not only does SES affect access to resources and the development of cognitive abilities, it has been found to strongly predict the academic achievement of students [11]. Both direct links (i.e. cognitive abilities) and indirect links (access to resources) of SES on academic achievement have been found to be significant.

Socioeconomic status appears to be important in academic achievement and academic self-efficacy [2] [3] [8] [12]-[14]. The relationship between self-efficacy and academic performance denotes that individuals raised in homes of lower SES report lower levels of self-efficacy [3] [15]. Shah et al. (2012) alternatively reported a positive relationship between academic achievement and familial SES. Although this connection has not been found to be causal, the association between SES and self-efficacy signifies that certain demographic variables influence the beliefs that one develops concerning his or her ability to perform in academics. Students from lower SES backgrounds are more likely to come from homes where parent(s) did not attain a degree beyond a high school diploma [16]. Additionally, students who originate from a home where no college degree has been earned are less likely to be encouraged by parents to attend college [17], and they are likely to hold misperceptions about postsecondary education [18]. A significant amount of research has focused on SES and how it relates to the availability of financial aid, academic guidance, and encouragement from parents, as well as access to institutions of higher learning [6] [16].

Meta-analyses have been conducted on the effect of familial SES on academic achievement. Small to medium effect sizes have been found between these two variables. White (1982) found a small to medium effect size between SES and academic achievement $(r=0.25)$ [19]. Sirin (2005) found an effect size of $r=0.29$, which was also a small to medium effect. The home environment from which a student originates impacts the level of academic achievement that the student reaches. Lower SES homes have been characterized as being less organized and providing fewer learning opportunities [20] [21]. Dilworth-Bart (2012) stated that individuals who came from a higher SES background were likely to receive constant and consistent care-giving, psychosocial resources, and more favorable learning opportunities [22]. Individuals who come from a lower SES social class are less likely to experience parental teaching, receive less cognitive stimulation, have reduced exposure to grade-level appropriate books, and are taught fewer academic skills [4]. The characteristics of the home environment, which are related to SES, affect the scholastic attitude, and the academic skills that a student develops. It also affects the quality of educational resources that individuals have access to. In sum, low SES homes and environments do not afford children the same opportunities to develop the cognitive abilities, academic beliefs, and academic aspirations that more affluent environments may offer.

Parents exert additional influences on the educational attitudes and achievements that their children will exhibit. Parents are the primary source of beliefs and attitudes towards academic studies [5]. Parental reactions to behaviors and parental modeling of appropriate behaviors affect the learning of students. These behaviors are reinforced by the educational system, particularly by teachers.

Parents who are able to create a positive environment, encourage the development academic self-efficacy and enhance motivation in their children. Parents' aspirations for success in school are positive predictors of their children's aspirations [23]. In a study conducted by Garg, Kauppi, Lewko, and Urajnik (2002), parental involvement was examined in relation to academic self-efficacy. This study found parental influence to account for a significant amount of the variance in educational ability and the instilling of the perspective that education was rewarding [24]. They also found that SES had significant effects on the involvement of parents in the educational pursuits of their children. Parents' educational level also was related to the amount of involvement that parents had in their students' school work. Although SES did not have a direct effect in this study, the presence 
of SES as a contributor to the model was significant. Parents are important sources of knowledge and modeling, especially early in child development [24]. Other research has also expounded upon other social supports and modeling processes that influence educational outcomes [25]. Such research suggests that peers and faculty mentors can have a tremendous impact on post-secondary success [25].

Parents have been found to be motivating factors in students' success in post-secondary institutions [26]. Sanchez, Reyes, and Singh (2005) found that a parent's encouragement and support was a significant predictor of enrolling in college and graduating. This finding fits Bandura's (1986) vicarious learning and modeling dimensions of self-efficacy theory. Parents who supported students in going to class, helped with homework, and encouraged matriculation in college bolstered academic success in their children. Many students, in turn, stated that they were motivated to earn a higher degree in order to repay their parents for their help and support. Vicarious learning, therefore, not only serves as a bolster of academic self-efficacy through the observation of models succeeding, but can also provide examples of other alternatives [27].

Bandura et al. (2001) found that socioeconomic status had a mediating effect on children's academic selfefficacy. They found that parents who were able to instill higher levels of academic achievement were more likely to develop higher academic aspirations. The stronger that parents felt that they were able to affect their children's academic success (relating to their own self-efficacy), the more motivated they were to nurture such potential. Underscoring parents' perceived self-efficacy was the level that children themselves had achieved [26]. Therefore, students who are able to develop high levels of academic self-efficacy are unlikely to be dismayed by external events. Such an attribute turns perceived abilities into actual achievements.

Usher and Pajares (2006) found that self-mastery experiences were predictive of academic self-efficacy, but only for students who fell within the average to high-average range of academic achievement [28]. These findings indicate that students are more likely to engage in a task when they feel that success in performing the task can be reached. Students who do not have mastery experiences may be susceptible to developing attitudes of avoidance. Just as success buttresses confidence, failure elicits the perception of a lack of ability and performance suffers. A student receiving a failing grade may, in consequence, develop the notion that he or she cannot succeed in that particular course or area. In light of familial SES and access to academic resources, individuals who are not given adequate opportunities to gain mastery experiences in school settings are less likely to have a high sense of academic self-efficacy.

The research on self-efficacy has been extensive and widely accepted. Past research has been greatly beneficial in identifying variables (such as SES) underlying academic success, and ultimately career accomplishment. However, further research is needed to examine the impact that these variables have on perceived academic success. The aim of this research project was to examine the effects of socioeconomic status, parental involvement, and academic self-efficacy on academic success.

\section{Hypotheses}

Hypothesis 1: It is hypothesized that students who come from a higher SES will have higher levels of selfefficacy.

Hypothesis 2: Parental involvement will be predictive of the self-regulated learning skills that students have developed.

Hypothesis 3: As academic self-efficacy increases, the outcome expectations (or the expected earning of higher degrees) will increase in students.

Hypothesis 4: The effect of familial SES on self-efficacy in students will be mediated by parental involvement.

\section{Method}

\subsection{Participants}

Undergraduate students $(N=298)$ in introductory psychology courses at a southern university, completed an online survey. The age range was 18 to 53 with a mean age of $19.7(S D=2.3)$. In terms of gender, $54 \%(n=160)$ were male and 46\% ( $n=138)$ were female. Participants' ethnicities were African American (19\%), Asian (2\%), Caucasian (73\%), Hispanic (1\%), Native American (2\%), and Bicultural (3\%). Year classification was predominately Freshman (60\%), but Sophomores (17\%), Juniors (7\%), and Seniors (16\%) were also represented. 


\subsection{Instruments}

A sociodemographic questionnaire was developed by the researchers. This survey included questions regarding the participants age, race, gender, year in school, high school GPA, current college GPA, household income, desired level of education, highest level of education achieved by mother and father, number of family members, highest level of education achieved by an immediate family member, number of credit hours currently enrolled in, current employment, number of hours worked per week, and funding for education. The sociodemographic questionnaire provided the necessary information regarding the SES of the participant. This included asking the participant to identify the average yearly income of his or her family of origin. The highest level of education desired served as the outcome expectation in college academics. It included the options of Associates degree, Bachelor's degree, Master's degree, and Doctorate degree. This variable was selected as the outcome measure because it evaluated the academic standards that the student has set for himself or herself, as well as the perceived success that he or she will have in his or her college career. Prior to data analysis, all surveys were de-identified in order to ensure anonymity and to protect participant information.

\subsection{Academic Self-Efficacy}

The Multidimensional Scales of Perceived Self-Efficacy (MSPSE) developed by Bandura (1989) was used to assess academic self-efficacy [29]. This measurement includes nine subscales: Enlisting Social Resources (4 items), Academic Achievement (9 items), Self-Regulated Learning (11 items), Leisure-Time Skill and Extracurricular Activities (8 items), Self-Regulatory Efficacy to Resist Peer Pressure (9 items), Meet Other’s Expectations (4 items), Social Self-Efficacy (4 items), Self-Assertive Efficacy (4 items), and Enlisting Parental and Community Support (4 items). All subscales will be used in this study. Additionally, a total score for selfefficacy can be calculated. The MSPSE has shown high reliability and validity. This measurement was also proven to have sufficient divergent and construct validity [30]. Each item is arranged on a 7-point Likert-type scale ranging from 1 (not well at all) to 7 (very well). The larger the overall score, the higher the self-efficacy of the student (Williams \& Coombs, 1996). Examples of questions are: "How well can you get teachers to help you when you get stuck on school work" and "How well can you concentrate on school subjects" [30].

\subsection{Perceptions of Parental Involvement}

The Perceptions of Parental and Teacher Involvement Scale (PPTIS) assesses both parental and teacher support that students perceive they are receiving, but was adapted for this study and only items referencing parents were included. The PPTIS includes a total of eight base statements with the terms parent or teacher substituted to form 16 total items. Hence, parental monitoring and support was represented by four items. This scale has shown appropriate levels of reliability and has been positively correlated to students' mastery goals and performance goals [31].

\subsection{Procedure}

Participants were university students and were therefore able to give informed consent. After approval from the Institutional Review Board, participants were recruited through in-class presentations of the study and through contact via email. During the overview, either in-class or through email, students were given information concerning the study and how to access the survey online. Some of the course instructors offered extra credit for those that participated in the study. For students who did not wish to participate in the study, an alternate means of obtaining extra credit was offered. It took approximately 30 minutes to complete the survey.

\section{Results}

\subsection{Preliminary Analyses}

Data screening was conducted to screen for missing values, outliers, and to verify the meeting of assumptions. Deleting cases due to missing values is a common approach when data cleaning [32] and missing values surpassing $20 \%$ can affect study validity [33]. During this process, 10 cases were deleted due to more than $20 \%$ of the items of their surveys not being completed. A mean substitution was inserted for missing values in the MSPSE and the Perceptions of Parental Involvement scale for cases with less than $20 \%$ of items missing. The assumptions of normality, independence, homoscedasticity, and linearity were met. In order to better facilitate 
the analysis of SES, and to corroborate findings with currently established economic classes, family income was coded into three groups, lower class, middle class, and upper class. These socioeconomic classes were determined by the classification system set forth by the US Department of Commerce (2010) [34]. In the relevant report, they identified the middle class as having a cut-off, or lowest quartile, at $\$ 50,800 /$ year. The US Department of Commerce found that the median middle-class income was $\$ 80,600$ a year, with the highest quartile reaching $\$ 122,800$ a year. In following these guidelines as closely as possible, the above mentioned groups were designated by the following incomes: lower class $\$ 0-\$ 50,000$, middle class $\$ 50,001-\$ 100,000$, and upper class $\$ 100,001$ and above. Finally, in order to determine if group differences existed between genders and SES, an ANOVA was conducted which resulted with no statistically significant differences found, $F(1,294)=1.522, p$ $=0.218$. A correlational analysis was conducted in order to determine the relationships between the variables of self-efficacy, familial SES, parental involvement, and parental college experience. All variables were significantly correlated. The results from the correlational analysis denote that parental college experience, familial SES, and parental involvement in their child's academics are positively related to self-efficacy. See Table 1 for results.

\subsection{Analysis of Variance}

A one way analysis of variance (ANOVA) was conducted to test the hypothesis that familial SES groups were associated with different levels of self-efficacy in college students. The overall self-efficacy score was used as the dependent variable in this model. The independent variable was the level of familial SES. Results showed that familial SES level was significant, with different levels of self-efficacy in college students, $F(2,295)=$ 3.040, $p=0.049, \eta p^{2}=0.020$. However, post-hoc analysis using Bonferroni pairwise comparison indicated that there were no statistically significant differences between working class $(M=277.97, S D=42.55)$, middle class $(M=289.47, S D=38.63)$, and upper class $(M=291.81, S D=35.92)$. The effect size (partial eta squared) of 0.020 denotes a small to medium effect.

The second hypothesis stated that self-efficacy would be predictive of outcome expectations in college students. The outcome expectation was operationalized as the level of education that the student desires to achieve. A logistic regression analysis was used to test this hypothesis. The subscales (self-regulated learning and academic achievement) of the Multidimensional Scales of Perceived Self-Efficacy were included in the model as predictors of the outcome variable (expectation of desired level of education), which was operationalized as earning an undergraduate degree versus a graduate degree. Results indicate that the overall model was ( $-2 \log$ Likelihood $=371.197$ ) significantly reliable in distinguishing those desiring undergraduate and graduate degrees $\left(\chi^{2}(2)=7.702, p=0.021\right)$. This model correctly classified $65.8 \%$ of the cases. Regression coefficients are presented in Table 2. Wald statistics indicate that self-regulated learning and academic achievement significantly predicts level of education desired. The odds ratio for this variable indicated that as self-regulated learning and academic achievement increase, the odds of the outcome, or academic expectations, also increase. Finally, the Hosmer and Lemeshow's statistic was calculated and found to be nonsignificant $\left(\chi^{2}(8)=1.241, p=0.996\right)$, which further validates the goodness-of-fit for this model.

Table 1. Correlational analysis results.

\begin{tabular}{cccccc}
\hline Variable & 1 & 2 & 3 & 4 & 5 \\
\hline 1. Father college & & & & & \\
2. Mother college & $0.445^{* *}$ & & & \\
3. Familial SES & $0.310^{* *}$ & $0.272^{* *}$ & & \\
4. Self-efficacy & $0.161^{* *}$ & $0.171^{* *}$ & $0.130^{*}$ & & \\
5. Parental involvement & $0.222^{* *}$ & $0.284^{* *}$ & $0.180^{*}$ & $0.393^{* *}$ \\
\hline
\end{tabular}

Note: ${ }^{*} p<0.05,{ }^{* *} p<0.01$.

Table 2. Regression coefficients for level of education desired.

\begin{tabular}{cccccc}
\hline & $\beta$ & Wald & $d f$ & $p$ & Odds ratio \\
\hline SR learning & 0.031 & 4.883 & 1 & 0.027 & 1.032 \\
Acad. ach. & 0.002 & 0.012 & 1 & 0.912 & 1.002 \\
Constant & -0.989 & 1.643 & 1 & 0.200 & 0.372 \\
\hline
\end{tabular}


In examining the third hypothesis, parental involvement was designated as the predictive variable and the Academic Achievement Self-Efficacy dimension of the MSPSE was used as the outcome variable. Both subscales of the parental involvement scale, parental academic monitoring and parental academic support, were included in the analysis. Regression results indicate that parental academic monitoring and support are significant predictors of Academic Achievement Self-Efficacy, $R^{2}=0.053, R_{\text {adj }}^{2}=0.047, F(2,295)=8.311, p<0.001$. Parental involvement accounted for $4.7 \%$ of the variance in college students perceived academic achievement efficacy expectations. Parental academic support was the only significant predictor. Table 3 illustrates the regression coefficients for this model.

\subsection{Mediation Analysis}

The final hypothesis stated that the effect of familial SES on overall student self-efficacy would be mediated by parental involvement. Previous statistical analyses have shown that familial SES and parental involvement are significant predictors of self-efficacy and level of education desired by students. Iacobucci (2012) examined the use of categorical data in mediation analysis. In her article, she states that, "If the independent variable, $X$, is (categorical [35]), but $M$ and $Y$ are continuous, the standard techniques are perfectly suitable...” (p. 2). Therefore, the variable familial SES, although categorical, was included in the mediation analysis as the independent variable. Familial SES was dummy coded so that the mediation analysis could be conducted. This analysis supported parental involvement as a mediator $(\beta=0.380, p<0.001$ ) as familial SES (working $\beta=-0.064, p=0.265$; upper $\beta=0.010, p=0.859$ ) became a non-significant predictor of Overall Self-efficacy. See Table 4 for the correlation coefficients of the mediation analysis.

\section{Discussion}

This study intended to expand the knowledge of factors that influenced college success. Much of the research that has evaluated SES and academic success has looked into the accessibility that SES provides to higher education for low-income students. This study examined whether familial SES influenced levels of self-efficacy in students. The results indicated that familial SES was related to the level of self-efficacy of college students. The positive relationship between these two variables indicates that as familial SES increases so does self-efficacy. It is important to point out that although familial SES is a significant predictor of self-efficacy, the effect size is small to medium. It is therefore assumed that the influence of familial SES is likely to be manifested though various mechanisms.

According to Bandura (1977), having appropriate models from whom to learn vicariously is an influential means of developing self-efficacy. Familial SES is positively correlated with parents having gone to college, thus supporting past results that level of education increases and socioeconomic status vary together. The findings of this study also show a positive relationship between familial SES and self-efficacy. The relationship between parents having attended college and academic self-efficacy is significant and moves in a positive direction. Therefore, one

Table 3. Regression coefficients for parental involvement as predictors of academic self-efficacy.

\begin{tabular}{ccccccc}
\hline & B & $\beta$ & $t$ & $p$ & Bivariate $r$ & Partial $r$ \\
\hline Parental support & 0.483 & 0.216 & 3.112 & $0.002^{*}$ & 0.230 & 0.178 \\
Parental monitoring & 0.050 & 0.025 & 0.361 & 0.719 & 0.149 & 0.021 \\
\hline
\end{tabular}

Note: academic achievement self-efficacy (outcome variable).

Table 4. Correlation coefficients for mediation analysis.

\begin{tabular}{cccc}
\hline Variable & 1 & 2 & 3 \\
\hline 1. Parental involvement & - & & \\
2. Familial SES & $0.180^{* *}$ & - & - \\
3. Overall self-efficacy & $0.393^{* *}$ & $0.130^{*}$ & 286.535 \\
$M$ & 28.171 & 1.902 & 39.592 \\
\hline
\end{tabular}

Note: ${ }^{*} p<0.05 .,{ }^{* *} p<0.01$. 
potential mechanism through which familial SES may impact self-efficacy is through the modeling of academic success by parents. As noted by Choy (2001), students who had parents who attended college were more prepared to meet the demands of the academic rigors of post-secondary learning. Students who have parents who attended college have appropriate models from whom they can learn attitudes and behaviors that are likely to increase their self-efficacy as it relates to academics.

Another finding was the relationship between the mother having gone to college and academic self-efficacy versus the comparable relationship for the father having gone to college. This may be due to the traditional role of mothers being primary care givers and academic supporters, especially during the early years of schooling. A household that has a mother who has achieved higher learning is related to higher levels of self-efficacy in children. This relationship was found to be stronger for mothers than for fathers, although fathers having attended college were also significantly correlated to academic beliefs. The overarching significance in these findings is that there is a significant, positive relationship between parents who have attended college and levels of self-efficacy in children.

The second hypothesis stated that higher academic self-efficacy would be predictive of higher levels of education desired in students. The results suggest that a higher level of self-efficacy is predictive of the student being more likely to pursue higher-level degrees. Certain facets of self-efficacy were significant predictors of higher academic pursuits. The results suggest that students who have learned to self-regulate their learning are more likely to seek advanced degrees. Self-regulation is an important academic attitude because it denotes that the individual has a capacity to "override one's thoughts, emotions, impulses, and automatic or habitual behaviors" [37]. Dedication to studies will provide greater mastery experiences, which has been linked to increased self-efficacy. Furthermore, students who believe in their ability to succeed in college and graduate, are more likely to pursue such degrees. According to Social Cognitive Theory, individuals who attain mastery experiences in certain fields are likely to develop higher self-efficacy in those fields [36]. Thus, students who have been able to develop studying and learning skills that have been adaptable and beneficial in earning high marks are likely to have had academic mastery experiences and to have developed a higher sense of self-efficacy in the academic realm.

The third hypothesis examined and found support for the predictive nature of parental involvement on academic self-efficacy. As mentioned, parents are likely to act as models for children, as well as sources of support and encouragement for academic performance. Only the parental support scale was a significant predictor. The parental monitoring scale was not a significant predictor of academic self-efficacy.

The results indicate that parents who are supportive, who offer encouragement and assistance, are more likely to help their college students develop a higher sense of academic self-efficacy. According to Kristjansson and Sigfusdottir (2009) parental support can take the form of parental accessibility, open discussions about life and academic progress, warmth, and advice [38]. Parents who display such attitudes and behaviors are likely to have a significant impact on the academic performance of their students. More importantly, parents who adopt and apply supportive tendencies instill in their students the beliefs that he or she can succeed in their educational pursuits.

In the final analysis, a mediation effect was established between familial SES, parental support, and selfefficacy. Familial SES became a nonsignificant predictor once parental support was included as a mediating variable. This finding demonstrates the tremendous impact that parents can have on their students' development of self-efficacy. Students who perceive their parents as supportive and interested in their academic pursuits are more likely to have a higher level of self-efficacy, even if they come from a lower socioeconomic class. Even though students who are from high SES are more likely to have parents who attended college and are more likely to have greater access to institutions of higher learning [6] [16], their level of self-efficacy is mediated by how active a role their parents take in their academic lives. Just as in any endeavor, college students continue to need advice, support, and encouragement from parents in order to bolster their self-efficacy and academic success.

\section{References}

[1] Bandura, A. (1986) Social Foundations of Thought and Action: A Social Cognitive Theory. Prentice-Hall, Englewood Cliffs.

[2] Cheung, S.Y. and Andersen, R. (2003) Time to Read: Family Resources and Educational Outcomes in Britain. Journal of Comparative Family Studies, 34, 413-434.

[3] Weiser, D.A. and Riggio, H.R. (2010) Family Background and Academic Achievement: Does Self-Efficacy Mediate 
Outcomes? Social Psychology and Education, 13, 367-383. http://dx.doi.org/10.1007/s11218-010-9115-1

[4] Tucker-Drob, E.M. and Harden, K.P. (2012) Intellectual Interest Mediates Gene $\times$ Socioeconomic Status Interaction on Adolescent Academic Achievement. Child Development, 83, 743-757. http://dx.doi.org/10.1007/s11199-011-0055-9

[5] Sainz, M., Palmen, R. and Garcia-Cuesta, S. (2012) Parental and Secondary School Teachers Perceptions of ICT Professionals, Gender Differences and Their Role in the Choice of Studies. Sex Roles, 66, 235-249. http://dx.doi.org/10.1007/s11199-011-0055-9

[6] Choy, S. (2001) Students Whose Parents Did Not Go to College: Postsecondary Access, Persistence, and Attainment. Findings from the Condition of Education, 2001. Retrieved from EBSCO Host.

[7] Bui, V.T. (2002) First-Generation College Students at a Four-Year University Background: Characteristics, Reasons for Pursuing Higher Education, and First-Year Experiences. College Student Journal, 36.

[8] Shah, M., Atta, A., Qureshi, M.I. and Shah, H. (2012) Impact of Socio Economic Status (SES) of Family on the Academic Achievements of Students. Gomal University Journal of Research, 28, 12-17.

[9] Altschul, I. (2012) Linking Socioeconomic Status to the Academic Achievement of Mexican American Youth through Parental Involvement in Education. Journal of the Society for Social Work and Research, 3, 13-30. http://dx.doi.org/10.5243/jsswr.2012.2

[10] Bradley, R.H., Corwyn, R.F., McAdoo, H.P. and Garcia Coll, C. (2001) The Home Environments of Children in the United States. Part 1: Variations by Age, Ethnicity, and Poverty Status. Child Development, 5, 1844-1867. http://dx.doi.org/10.1111/1467-8624.t01-1-00382

[11] Sirin, S.R. (2005) The Relationship between Socioeconomic Status and School Outcomes: Meta Analytic Review of Research, 1990-2000. Dissertation Abstracts International: Section B: The Sciences and Engineering, 64, 4088.

[12] Gottfried, A.W., Gottfried, A.E., Bathurst, K., Guerin, D.W. and Parramore, M.M. (2003) Socioeconomic Status in Children's Development and Family Environment: Infancy through Adolescence. In: Bornstein, M.H. and Bradley, R.H., Eds., Socioeconomic Status, Parenting, and Child Development, Lawrence Erlbaum, Mahwah, 189-207.

[13] Masten, A.S., Hubbard, J., Gest, S.D., Tellegen, A., Garmezy, N. and Ramirez, M. (1999) Adversity, Resources, and Resilience: Pathways to Competence from Childhood to Late Adolescence. Developmental and Psychopathology, 11, 143-169. http://dx.doi.org/10.1017/S0954579499001996

[14] Teachman, J. (1987) Family Background, Educational Resources and Educational Attainment. American Sociological Review, 52, 548-557. http://dx.doi.org/10.2307/2095300

[15] Coleman, P.K. and Karraker, K.H. (1997) Self-Efficacy and Parenting Quality: Findings and Future Applications. Development Review, 18, 47-85. http://dx.doi.org/10.1006/drev.1997.0448

[16] Engle, J., Bermeo, A. and O’Brien, C. (2006) Straight from the Source: What Works for First-Generation College Students. The Pell Institute for the Study of Opportunity in Higher Education, Washington DC.

[17] Billson, J.M. and Terry, M.B. (1982) In Search of the Silken-Purse: Factors in Attrition among First-Generation Students. Proceedings of the Annual Meeting of the Association of American Colleges, Denver.

[18] Vargas, J.H. (2004) College Knowledge: Addressing Information Barriers to College. The Education Resources Institute (TERI), Boston.

[19] White, K.R. (1982) The Relation between Socioeconomic Status and Academic Achievement. Psychological Bulletin, 91, 461-481. http://dx.doi.org/10.1037/0033-2909.91.3.461

[20] Evans, G.W. (2004) The Environment of Childhood Poverty. American Psychologist, 59, 77-92. http://dx.doi.org/10.1037/0003-066X.59.2.77

[21] Vernon-Feagans, L., Garret-Peters, P., Willoughby, M. and Mills-Koonce, R. (2012) Chaos, Poverty, and Parenting: Predictors of Early Language Development. Early Childhood Research Quarterly, 27, 339-351. http://dx.doi.org/10.1016/j.ecresq.2011.11.001

[22] Dilworth-Bart, J. (2012) Does Executive Function Mediate SES and Home Quality Associations Readiness? Early Childhood Research Quarterly, 27, 416-425.

[23] Wentzel, K.R. (1998) Parents’ Aspirations for Children’s Educational Attainments: Relations to Parental Beliefs and Social Address Variables. Merrill-Palmer Quarterly, 44, 20-37.

[24] Garg, R., Kauppi, C., Lewko, J. and Urajnik, D. (2002) A Structural Model of Educational Aspirations. Journal of Career Development, 29, 87-108. http://dx.doi.org/10.1023/A:1019964119690

[25] Edman, J.L. and Brazil, B. (2007) Perceptions of Campus Climate, Academic Efficacy and Academic Success among Community College Students: An Ethnic Comparison. Social Psychology and Education, 12, 371-383. http://dx.doi.org/10.1007/s11218-008-9082-y

[26] Bandura, A., Barbaranelli, C., Caprara, G.V. and Pastorelli, C. (2001) Self-Efficacy Beliefs as Shapers of Children’s Aspirations and Career Trajectories. Child Development, 72, 187-206. http://dx.doi.org/10.1111/1467-8624.00273 
[27] Sanchez, B., Reyes, O. and Singh, J. (2005) Makin’ It in College: The Value of Significant Individuals in the Lives of Mexican American Adolescents. Journal of Hispanic Higher Education, 5, 48-67. http://dx.doi.org/10.1177/1538192705282570

[28] Usher, E.L. and Pajares, F. (2006) Sources of Academic and Self-Regulatory Efficacy Beliefs of Entering Middle School Students. Contemporary Education Psychology, 31, 125-141. http://dx.doi.org/10.1016/j.cedpsych.2005.03.002

[29] Bandura, A. (1989) The Multidimensional Self-Efficacy Scales. Unpublished Test, Stanford.

[30] Williams, J.E. and Coombs, W.T. (1996) An Analysis of the Reliability and Validity of Bandura's Multidimensional Scales of Perceived Self-Efficacy. Proceedings of the Annual Meeting of the American Educational Research Association, New York, 8-12 April 1996.

[31] Regnar, I., Loose, F. and Dumas, F. (2009) Students' Perceptions of Parental and Teacher Academic Involvement: Consequences on Achievement Goals. European Journal of Psychology of Education, 24, 263-277. http://dx.doi.org/10.1007/BF03173016

[32] Karmaker, A. and Kwek, S. (2007) An Iterative Refinement Approach for Data Cleaning. Intelligent Data Analysis, 11, 547-560.

[33] Schulz, K.F. and Grimes, D.A. (2002) Sample Size Slippages in Randomized Trials: Exclusions and the Lost and Wayward. The Lancet, 359, 781-785. http://dx.doi.org/10.1016/S0140-6736(02)07882-0

[34] US Department of Commerce, Economics and Statistics Administration, Office of the Vice President of the United States (2010) Middle Class in America. http://www.commerce.gov/news/fact-sheets/2010/01/25/middle-class-america-task-force-report-pdf

[35] Iacobucci, D. (2012) Mediation Analysis and Categorical Variables: The Final Frontier. Journal of Consumer Psychology, 22, 582-594. http://dx.doi.org/10.1016/j.jcps.2012.03.006

[36] Bandura, A. (1977) Self-Efficacy: Toward a Unifying Theory of Behavioral Change. Psychological Review, 84, 191215. http://dx.doi.org/10.1037/0033-295X.84.2.191

[37] Gailliot, M.T., Mead, N.L. and Baumeister, R.F. (2012) Self-Regulation. In: John, O.P., Robins, R.W. and Pervin, L.A., Eds., Handbook of Personality: Theory and Research, The Guilford Press, New York, 472-491.

[38] Kristjansson, A.L. and Sigfusdottir, I.D. (2009) The Role of Parental Support, Parental Monitoring, and Time Spent with Parents in Adolescent Academic Achievement in Iceland: A Structural Equation Model of Gender Differences. Scandinavian Journal of Educational Research, 53, 481-496. http://dx.doi.org/10.1080/00313830903180786 